Check for updates

Cite this: RSC Adv., 2018, 8, 13671

Received 1st March 2018

Accepted 5th April 2018

DOI: $10.1039 / \mathrm{c} 8 \mathrm{ra01796d}$

rsc.li/rsc-advances

\title{
Heterogeneous Co-catalyzed direct 2-alkylation of azoles with ethers $\uparrow$
}

\author{
Ke Yang, (D) Dashan Li, Lei Zhang, Qun Chen* and Tiandi Tang (D) * \\ The direct 2-alkylation of oxazoles and thiazoles with ethers through cross-dehydrogenative coupling \\ reaction using Co-containing mesoporous zeolite ETS-10 as the heterogeneous catalyst is described. \\ The basic Co-containing mesoporous zeolite ETS-10 catalyst facilitates this cross-dehydrogenative \\ coupling reaction through metal-base synergy catalytic principle.
}

Transition metal-catalyzed $\mathrm{C}-\mathrm{H}$ bond functionalization reaction has become one of the most efficient methods for selective $\mathrm{C}-\mathrm{C}$ and $\mathrm{C}-\mathrm{X}$ bond formation in synthetic chemistry. ${ }^{1}$ Current primarily transition metal-catalyzed $\mathrm{C}-\mathrm{H}$ bond functionalization reactions rely on homogeneous metal catalysts, in most cases, which also need extra basic or acidic additives and catalyst ligands. ${ }^{2}$ Recently, considerable efforts have been devoted to heterogeneous catalysis, ${ }^{3}$ because heterogeneous transition metal catalysts not only provide easy product-catalyst separation and catalyst recycling features, but also afford additional important active sites through support materials in $\mathrm{C}-\mathrm{H}$ bond functionalization. It is noteworthy that zeolites are crystalline porous support materials with good chemical and thermal stability. Especially, the unique frameworks of zeolites present basic or acidic properties in catalytic performance, which have been widely used in the organic transformations. ${ }^{4}$ Therefore, developing novel heterogeneous metal catalysts by using zeolites would be of prime synthetic value.

2-Substituted azoles are widely present in biological activities compounds, pharmaceuticals and organic functional materials. ${ }^{5}$ Most current methods for accessing 2-alkylazoles depend on the transition metal-catalyzed direct C-2-alkylation of azoles with alkylating reagents under basic conditions. ${ }^{6}$ However, the convenient and straightforward approach using non-functionalized ethers as alkylating reagents through crossdehydrogenative coupling is still rare. ${ }^{7}$ Very recently, Lu and Li group also demonstrated the cobalt-catalyzed crossdehydrogenative coupling reaction of oxazoles and ethers. ${ }^{7 a}$ It still suffered from certain limitations such as the restricted use of relatively harsh reaction conditions. One possible reason is that the cobalt catalyst is incompatible with base. For this reason, we believe that exploring the suitable bases could benefit this reaction.

Jiangsu Key Laboratory of Advanced Catalytic Materials \& Technology, School of Petrochemical Engineering, Changzhou University, 1 Gehu Road, Changzhou, Jiangsu 213164, China.E-mail: tangtiandi@cczu.edu.cn; chenqunjpu@yahoo.com

$\dagger$ Electronic supplementary information (ESI) available. See DOI: 10.1039/c8ra01796d
Mesoporous zeolite ETS-10 has a three-dimensional 12membered ring network and possesses relatively strong Lewis basicity. The basic characteristic is related to its framework that comprises corner sharing $\mathrm{TiO}_{6}{ }^{2-}$ octahedra and $\mathrm{SiO}_{4}$ tetrahedra as building units. In this manner, each $\mathrm{TiO}_{6}$ unit contributes two negative charges that are compensated by extra-framework cations $\left(\mathrm{Na}^{+}\right.$and $\left.\mathrm{K}^{+}\right){ }^{8}$ Considering the unique framework architectures and chemical compositions of zeolite ETS-10, we envisioned basic zeolite ETS-10 supported metal catalysts might facilitate this cross-dehydrogenative coupling reaction through metal-base synergy catalytic principle. Herein, we report the first example of Co-containing mesoporous zeolite ETS-10 catalyzed 2-alkylation of azoles with ethers through the crossdehydrogenative coupling reaction.

We began our study with the preparation of $3 \mathrm{wt} \%$ Cocontaining basic mesoporous zeolite ETS-10 (Co/METS-10). For comparison, $3 \mathrm{wt} \%$ Co-containing acidic mesoporous ZSM-5 (Co/MZSM-5) was also tested in this catalytic cycle. The cross-dehydrogenative coupling reaction of benzoxazole 1a and tetrahydrofuran 2a with Co/METS-10 was carried out in the presence of tert-butyl hydroperoxide (TBHP, 5.0-6.0 $\mathrm{M}$ in $n$ decane) at $100{ }^{\circ} \mathrm{C}$ under the $\mathrm{N}_{2}$ atmosphere, and the desired product 2-(tetrahydrofuran-2-yl)benzo[d] oxazole 3 a could be obtained in $80 \%$ yield (Table 1 , entry 1 ). Then acidic Co/MZSM-5 was examined in our reaction, however, this acidic heterogeneous catalyst Co/MZSM-5 was not compatible with our reaction system, indicating that the acidic support material MZSM-5 cannot promote this process (Table 1, entry 2). We also found that the yield of $\mathbf{3 a}$ was decreased using the reported $\mathrm{CoCO}_{3}$ catalyst under relatively mild conditions (Table 1 , entry 3 ). Furthermore, basic mesoporous Cu/METS-10, Fe/METS-10 and $\mathrm{Ni} / \mathrm{METS}-10$ were also prepared to investigate in our catalytic cycle, and the results demonstrated that Co/METS-10 exhibited the higher catalytic efficiency, indicating that Co/METS-10 is the optimal catalyst (Table 1, entries 4-6). After that, replacement of TBHP with other additives, such as $\mathrm{K}_{2} \mathrm{~S}_{2} \mathrm{O}_{8}$, 2,3-dichloro-5,6dicyanobenzoquinone (DDQ), di-tert-butyl peroxide (DTBP), dicumyl peroxide (DCP), benzoyl peroxide (BPO) and $t$-BuOOBz, caused either the low yield of desired product $3 \mathrm{a}$ or no reaction, 
suggesting that THBP is the optimal additives (Table 1, entries 7-12). In addition, no desired product 3a was detected in absence of additives (Table 1, entry 13). Finally, only $20 \%$ yield of 3a was examined when cobalt catalyst was absent in this process (Table 1, entry 14).

With the optimized conditions in hand, a substrate scope study of azole moiety was carried out firstly (Table 2). As we expected, the current catalytic system proceeded in good yields for the substituted benzoxazoles ( $\mathbf{3 b} \mathbf{b}-\mathbf{g})$. Both electron-donating and electron-withdrawing groups on the phenyl ring were tolerated in this catalytic cycle. Moreover, employing disubstituted oxazole $\mathbf{1 h}$ as the coupling partner, the desired product $\mathbf{3 h}$ was isolated in moderate yield. Besides, the scope study of aliphatic ethers was also tested in our cobalt catalysis system. Both linear aliphatic ethers and cyclic aliphatic ethers could be used to prepare the corresponding products in moderate to good yields $(\mathbf{3 i}-\mathbf{m})$. Next, we sought the substrate scope study of thiazoles and aliphatic ethers in the presence of basic Co/METS-10 catalyst. As shown in Table 3, different substituted benzo $[d]$ thiazoles generated the desired products in good yield (5a-e). Furthermore, different kinds of aliphatic ethers were also well tolerated in this catalytic cycle $(\mathbf{5} \mathbf{f}-\mathbf{j})$.

In order to provide some insights into the possible mechanism, a series of control experiments were carried out. The radical trapping experiment was firstly performed, which was found that the addition of TEMPO inhibited this reaction (Scheme 1a). It suggests that this reaction may be involving a radical pathway. Next, the investigations of TBHP and tetrahydrofuran with or without Co/METS-10 catalyst using TEMPO as a radical trapping reagent were also performed (Scheme 1b). In the presence of Co/ETS-10, the alkyl radical trapping product

Table 1 Optimization of reaction conditions ${ }^{a}$

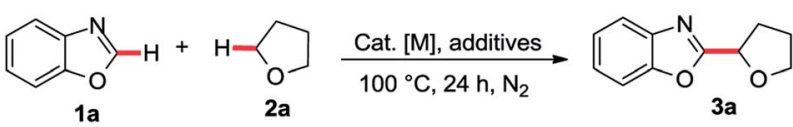

\begin{tabular}{llll}
\hline Entry & Catalyst & Additives & Yield $(\%)^{b}$ \\
\hline 1 & Co/METS-10 $(5 \mathrm{~mol} \%)$ & TBHP & $82(80)^{c}$ \\
2 & Co/MZSM-5 $(5 \mathrm{~mol} \%)$ & TBHP & 35 \\
3 & CoCO $_{3}(5 \mathrm{~mol} \%)$ & TBHP & 56 \\
4 & Cu/METS-10 $(5 \mathrm{~mol} \%)$ & TBHP & 50 \\
5 & Fe/METS-10 $(5 \mathrm{~mol} \%)$ & TBHP & 65 \\
6 & Ni/METS-10 $(5 \mathrm{~mol} \%)$ & TBHP & 38 \\
7 & Co/METS-10 $(5 \mathrm{~mol} \%)$ & $\mathrm{K}_{2} \mathrm{~S}_{2} \mathrm{O}_{8}$ & 0 \\
8 & Co/METS-10 $(5 \mathrm{~mol} \%)$ & DDQ & 0 \\
9 & Co/METS-10 $(5 \mathrm{~mol} \%)$ & DTBP & Trace \\
10 & Co/METS-10 $(5 \mathrm{~mol} \%)$ & DCP & 0 \\
11 & Co/METS-10 $(5 \mathrm{~mol} \%)$ & BPO & 42 \\
12 & Co/METS-10 (5 mol $\%)$ & $t$-BuOOBz & 60 \\
13 & Co/METS-10 $(5 \mathrm{~mol} \%)$ & - & 0 \\
14 & - & TBHP & 20
\end{tabular}

${ }^{a}$ Conditions: $1 \mathrm{a}(0.2 \mathrm{mmol}), \mathbf{2 a}(2.5 \mathrm{~mL}), 5 \mathrm{~mol} \%$ metal in catalyst, additives $(0.4 \mathrm{mmol}), 100{ }^{\circ} \mathrm{C}, 24 \mathrm{~h}, \mathrm{~N}_{2}$, yield. ${ }^{b}$ Yields are based on 1a, determined by crude ${ }^{1} \mathrm{H}$ NMR using dibromomethane as the internal standard. ${ }^{c}$ Isolated yield.
Table 2 Scope of oxazoles and ethers ${ }^{a}$

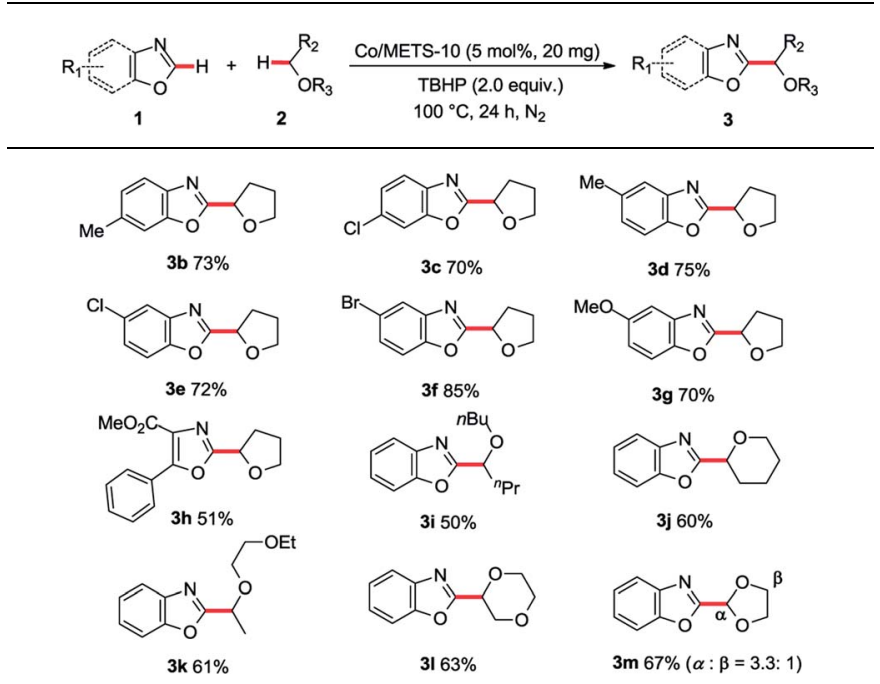

${ }^{a}$ Conditions: 1 (0.2 mmol), $2(2.5 \mathrm{~mL}), 3 \mathrm{wt} \% \mathrm{Co} / \mathrm{METS}-10(5 \mathrm{~mol} \%, 20$ $\mathrm{mg})$, TBHP $(0.4 \mathrm{mmol}), 100{ }^{\circ} \mathrm{C}, 24 \mathrm{~h}, \mathrm{~N}_{2}$, Isolated yield.

6 could be isolated in $89 \%$ yield when 2.0 equivalent of TBHP was added. It suggests that Co/METS-10 catalyst may play an important role in the process of alkyl radical generation. ${ }^{9}$ Moreover, some intermolecular H/D exchange of azole (9\% D) was observed when additional $\mathrm{D}_{2} \mathrm{O}$ was added in reaction system, suggesting a metal-mediated $\mathrm{C}-\mathrm{H}$ bond cleavage process is involved (see Scheme S1 in ESI $\dagger$ ). Finally, the intermolecular competition experiment was also carried out, indicating that electron density in phenyl rings of azoles does not affect the reaction rate (Scheme 2).

To gain further insight into this reaction mechanism, the electron state and the location as well as the dispersion of the

Table 3 Scope of thiazoles and ethers ${ }^{a}$

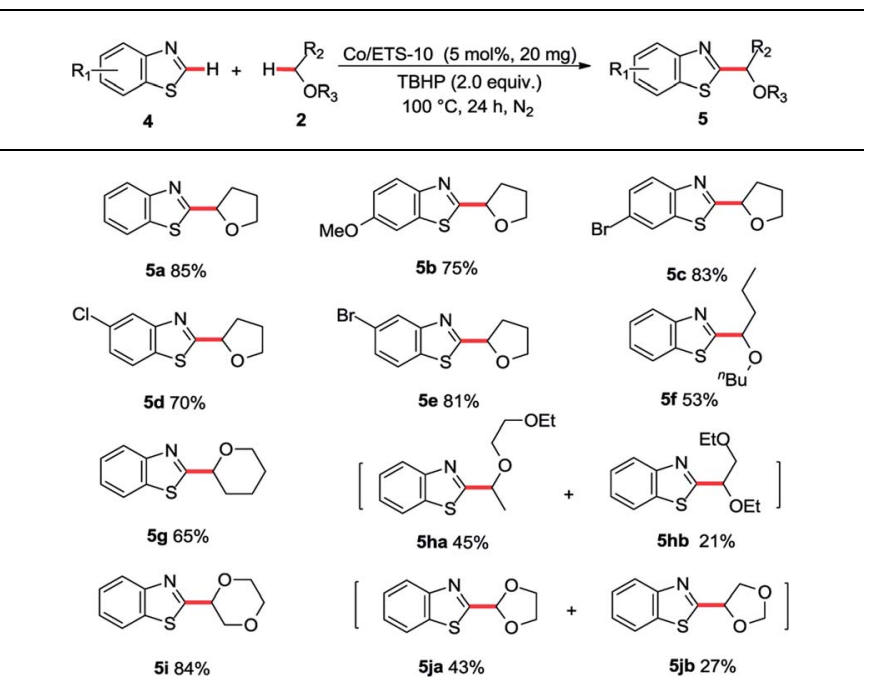

${ }^{a}$ Conditions: $4(0.2 \mathrm{mmol}), 2(2.5 \mathrm{~mL}), 3 \mathrm{wt} \% \mathrm{Co} / \mathrm{METS}-10(5 \mathrm{~mol} \%, 20$ $\mathrm{mg})$, TBHP (0.4 mmol), $100{ }^{\circ} \mathrm{C}, 24 \mathrm{~h}, \mathrm{~N}_{2}$, Isolated yield. 


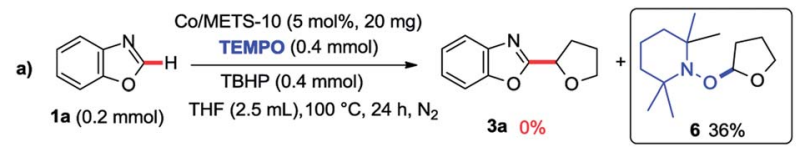

b)

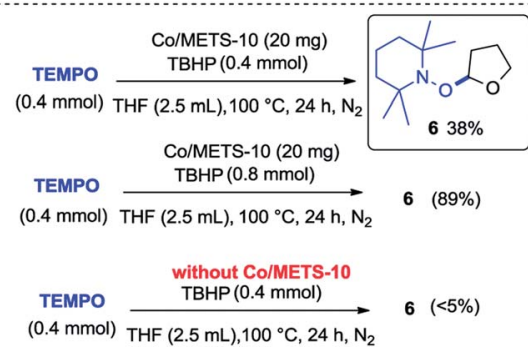

Scheme 1 The radical trapping experiments.
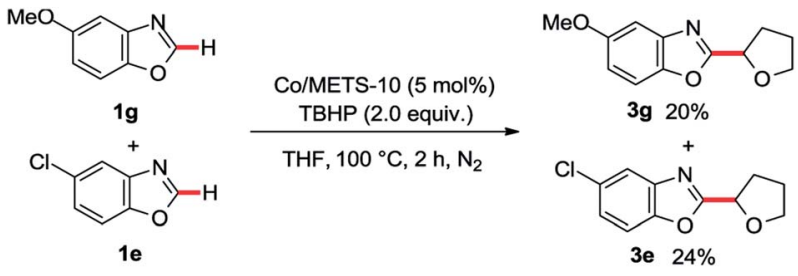

Scheme 2 The intermolecular competition experiment.

Co species in the Co/METS-10 catalyst were analyzed by X-ray photoelectron spectroscopy (XPS) and the transmission electron microscopy (TEM) techniques, respectively (see Fig. S1-S3 in $\mathrm{ESI}_{\dagger}^{\dagger}$ ). The results indicate that the $\mathrm{Co}^{\mathrm{II}}$ species are highly dispersed in the micropore and mesoporous channels of the $\mathrm{Co} /$ METS-10 catalyst (the details are described in the ESI $\dagger$ ).

On the basis of above results and the previous literatures, ${ }^{7 a, 9-11}$ the following plausible mechanistic pathway has been proposed in Scheme 3. It is believed that the Co(II)/METS-10 catalyst is transformed to the Co(III)/METS-10 in the presence of TBHP via a SET process with producing the corresponding $t$ BuO radical. ${ }^{10}$ Then alkyl radical $\mathbf{B}$ can be generated through $t$ BuO radical abstracts hydrogen atoms from $2 \mathbf{a}$. The metallization of $1 \mathrm{a}$ in the presence of $\mathrm{Co}(\mathrm{III}) / \mathrm{METS}-10$ provides the $\mathrm{Co}^{\mathrm{III}}$

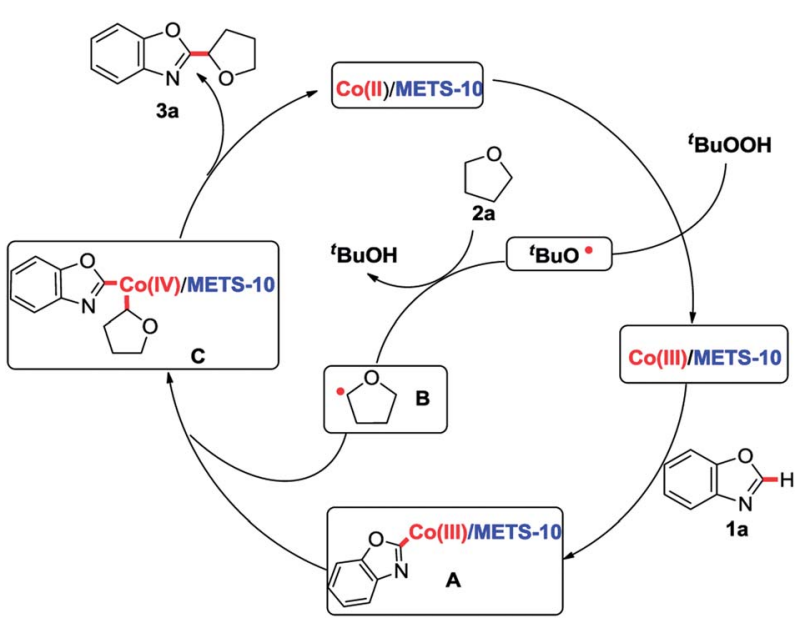

Scheme 3 A plausible catalytic cycle.

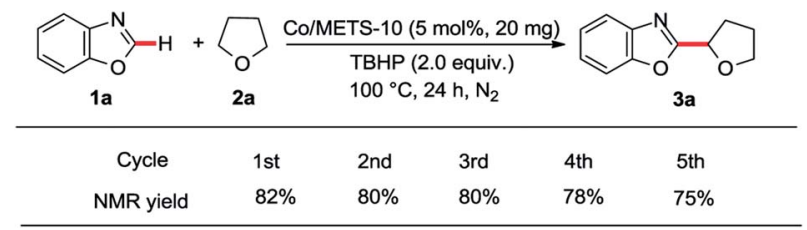

Scheme 4 The Co/METS-10 catalyst recyclability experiments.

intermediate $\mathbf{A}$, and subsequent oxidative addition of the radical $\mathbf{B}$ gives the $\mathrm{Co}^{\mathrm{IV}}$ intermediate $\mathbf{C},{ }^{\mathbf{1 1}}$ leading to the desired product 3a and regeneration of $\mathrm{Co}(\mathrm{II}) / \mathrm{METS}-10$ catalyst through reductive elimination.

To probe the recyclability of the Co/METS- 10 catalyst in this process, five round consecutive reactions of 1a with 2a were carried out under the recovered catalyst. We discovered that the catalytic activity of Co/METS-10 slightly decreased after five consecutive rounds with 75\% NMR yield (Scheme 4).

\section{Conclusions}

In summary, we have developed an efficient basic Co-containing mesoporous zeolite ETS-10 catalyzed direct 2-alkylation of azoles with aliphatic ethers. This transformation is the first example of cross-dehydrogenative coupling reactions through a basic heterogeneous Co/METS-10 catalyst. This catalytic system tolerates a variety of functional groups with good yields. Furthermore, this novel method provides an important complementary approach to access the important bioactive 2alkylated azoles derivatives.

\section{Conflicts of interest}

There are no conflicts to declare.

\section{Acknowledgements}

We gratefully acknowledge the financial support from the National Natural Science Foundation of China (21676030, 21776022 and 21702019). We are also grateful to Advanced Catalysis and Green Manufacturing Collaborative Innovation Center, Changzhou University for financial support.

\section{Notes and references}

1 For selected reviews, see: (a) J. He, M. Wasa, K. S. L. Chan, Q. Shao and J.-Q. Yu, Chem. Rev., 2017, 117, 8754; (b) Q. Lu and F. Glorius, Angew. Chem., Int. Ed., 2017, 56, 49; (c) Y. Yang, J. Lan and J. You, Chem. Rev., 2017, 117, 8787; (d) R.-Y. Zhu, M. E. Farmer, Y.-Q. Chen and J.-Q. Yu, Angew. Chem., Int. Ed., 2016, 55, 10578; (e) Q.-Z. Zheng and N. Jiao, Chem. Soc. Rev., 2016, 45, 4590; $(f)$ H. Kim and S. Chang, ACS Catal., 2016, 6, 2341; $(g)$ G. Qiu and J. Wu, Org. Chem. Front., 2015, 2, 169; (h) J. Miao and H. Ge, Eur. J. Org. Chem., 2015, 2015, 7859; (i) B. Liu, F. Hu and B.-F. Shi, ACS Catal., 2015, 5, 1863; (j) Z. Huang, H. N. Lim, F. Mo, M. C. Young and G. Dong, Chem. Soc. Rev., 2015, 44, 7764; (k) Z. Chen, B. Wang, J. Zhang, W. Yu, Z. Liu and Y. Zhang, 
Org. Chem. Front., 2015, 2, 1107; (l) S. D. Sarkar, W. Liu, S. I. Kozhushkov and L. Ackermann, Adv. Synth. Catal., 2014, 356, 1461; $(m)$ K. Gao and N. Yoshikai, Acc. Chem. Res., 2014, 47, 1208; (n) G. Rouquet and N. Chatani, Angew. Chem., Int. Ed., 2013, 52, 11726; (o) T. W. Lyons and M. S. Sanford, Chem. Rev., 2010, 110, 1147; (p) X. Chen, K. M. Engle, D.-H. Wang and J.-Q. Yu, Angew. Chem., Int. Ed., 2009, 48, 5094.

2 For selected recent examples, see: (a) P. Wang, P. Verma, G. Xia, J. Shi, J. X. Qiao, S. Tao, P. T. W. Cheng, M. A. Poss, M. E. Farmer, K. Yeung and J.-Q. Yu, Nature, 2017, 551, 489; (b) Y. Liu and H. Ge, Nature Chem., 2017, 9, 26; (c) J. M. Ahn, J. C. Peters and G. C. Fu, J. Am. Chem. Soc., 2017, 139, 18101; (d) S. Asghar, S. B. Tailor, D. Elorriaga and R. B. Bedford, Angew. Chem., Int. Ed., 2017, 56, 16367; (e) K. Yang, Q. Li, Y. Liu, G. Li and H. Ge, J. Am. Chem. Soc., 2016, 138, 12775; (f) F.-L. Zhang, K. Hong, T.-J. Li, H. Park and J.-Q. Yu, Science, 2016, 351, 252; $(g)$ Y. Xu, M. Young, C. Wang, D. Magness and G. Dong, Angew. Chem., Int. Ed., 2016, 55, 9084.

3 For selected recent reviews see: (a) S. Santoro, S. I. Kozhushkov, L. Ackermann and L. Vaccaro, Green Chem., 2016, 18, 3471; (b) A. J. Reay and I. J. S. Fairlamb, Chem. Commun., 2015, 51, 16289; For selected recent examples, see; (c) B. Paplal, S. Nagaraju, K. Sathish and D. Kashinath, Catal. Commun., 2018, 103, 110; (d) S. Warratz, D. J. Burns, C. Zhu, K. Korvorapun, T. Rogge, J. Scholz, C. Jooss, D. Gelman and L. Ackermann, Angew. Chem., Int. Ed., 2017, 56, 1557; (e) Q. Hu, X. Liu, G. Wang, F. Wang, Q. Li and W. Zhang, Chem.-Eur. J., 2017, 23, 17659; (f) S. Vásquez-Céspedes, A. Ferry, L. Candish and F. Glorius, Angew. Chem., Int. Ed., 2015, 54, 5772; (g) C. Bai, X. Yao and Y. Li, ACS Catal., 2015, 5, 884; $(h)$ M. Cao, D. $\mathrm{Wu}, \mathrm{W} . \mathrm{Su}$ and R. Cao, J. Catal., 2015, 321, 62.

4 For selected recent examples, see: (a) L. Wang, G. Wang, J. Zhang, C. Bian, X. Meng and F.-S. Xiao, Nature Commun., 2017, 8, 15240; (b) J. Zhang, L. Wang, Y. Shao, Y. Wang, B. Gates and F.-S. Xiao, Angew. Chem., Int. Ed., 2017, 56, 9747; (c) C. Wang, L. Wang, J. Zhang, H. Wang, J. P. Lewis and F.-S. Xiao, J. Am. Chem. Soc., 2016, 138, 7880; (d) S. Chen, Z. Shao, Z. Fang, Q. Chen, T. Tang, W. Fu, L. Zhang and T. Tang, J. Catal., 2016, 338, 38; (e) W. Fu, Y. Feng, Z. Fang, Q. Chen, T. Tang, Q. Yu and T. Tang, Chem. Commun., 2016, 52, 3115; $(f)$ W. Fu, T. Liu, Z. Fang, Y. Ma, X. Zheng, W. Wang, X. Ni, M. Hu and T. Tang, Chem. Commun., 2015, 51, 5890.
5 For selected examples, see: (a) J. V. Faria, P. F. Vegi, A. G. C. Miguita, M. S. dos Santos, N. Boechat and A. M. R. Bernardino, Bioorg. Med. Chem., 2017, 25, 5891; (b) H. S. Kumbhar, S. S. Deshpande and G. S. Shankarling, Dyes Pigm., 2016, 127, 161; (c) M. Kim, J. Jeon, J. Song, K. H. Suh, Y. H. Kim, K. H. Min and K. O. Lee, Bioorg. Med. Chem. Lett., 2013, 23, 3140; (d) S. R. Mandadapu, P. M. Weerawarna, M. R. Gunnam, K. R. Alliston, G. H. Lushington, Y. Kim, K.-O. Chang and W. C. Groutas, Bioorg. Med. Chem. Lett., 2012, 22, 4820; (e) I. K. Mangion, B. D. Sherry, J. Yin and F. J. Fleitz, Org. Lett., 2012, 14, 3458; (f) R. E. Martin, L. G. Green, W. Guba, N. Kratochwil and A. Christ, J. Med. Chem., 2007, 50, 6291.

6 For selected examples, see: (a) G. Tan, L. Zhang, X. Liao, Y. Shi, Y. Wu, Y. Yang and J. You, Org. Lett., 2017, 19, 4830; (b) C. M. Filloux and T. Rovis, J. Am. Chem. Soc., 2015, 137, 508; (c) X. Wu, C. Lei, G. Yue and J. S. Zhou, Angew. Chem., Int. Ed., 2015, 54, 9601; (d) X. Wu, J. W. T. See, K. Xu, H. Hirao, J. Roger, J. Hierso and J. S. Zhou, Angew. Chem., Int. Ed., 2014, 53, 13573; (e) T. Yao, K. Hirano, T. Satoh and M. Miura, Angew. Chem., Int. Ed., 2012, 51, 775.

7 (a) Y. Li, M. Wang, W. Fan, F. Qian, G. Li and H. Lu, J. Org. Chem., 2016, 81, 11743; (b) A. Correa, B. Fiserb and E. Gómez-Bengoa, Chem. Commun., 2015, 51, 13365; (c) Z. Xie, Y. Cai, H. Hu, C. Lin, J. Jiang, Z. Chen, L. Wang and Y. Pan, Org. Lett., 2013, 15, 4600; (d) T. He, L. Yu, L. Zhang, L. Wang and M. Wang, Org. Lett., 2011, 13, 5016.

8 (a) M. W. Anderson, O. Terasaki, T. Ohsuna, A. Philippou, S. P. MacKay, A. Ferreira, J. Rocha and S. Lidin, Nature, 1994, 367, 347; (b) M. Xiang, X. Ni, X. Yi, A. Zheng, W. Wang, M. He, J. Xiong, T. Liu, Y. Ma, P. Zhu, X. Zheng and T. Tang, ChemCatChem, 2015, 7, 521.

9 (a) Y. Li, F. Qian, M. Wang, H. Lu and G. Li, Org. Lett., 2017, 19, 5589; (b) K. Yang, X. Chen, Y. Wang, W. Li, A. A. Kadi, H.-K. Fun, H. Sun, Y. Zhang, G. Li and H. Lu, J. Org. Chem., 2015, 80, 11065.

10 (a) J. Kim, S. Cho, J. Joseph and S. Chang, Angew. Chem., Int. Ed., 2010, 49, 9899; (b) N. Turrà, U. Neuenschwander, A. Baiker, J. Peeters and I. Hermans, Chem.-Eur. J., 2010, 16, 13226.

11 (a) X. Wu, K. Yang, Y. Zhao, H. Sun, G. Li and H. Ge, Nat. Commun., 2015, 6, 6462; (b) J. Zhang, H. Chen, C. Lin, Z. X. Liu, C. Wang and Y. Zhang, J. Am. Chem. Soc., 2015, 137, 12990. 